\title{
Kriteria Yang Berpengaruh Dalam Penilaian Kinerja Karyawan Menggunakan Anaytical Hierarchy Process
}

\author{
Krisnadhi Hariyanto ${ }^{1}$, Eko Budi Satoto ${ }^{2}$
}

\begin{abstract}
Employee performance is the result of work that is achieved or the results that have been done or worked by an employee within the chores that are charged to the employee. The problem is a priority weighting of the factors and sub factors to get the solution in advance in accordance with the order of priority. In this study the data collected is done by direct observation, interviews, questionnaires and literature. The data are processed to determine the priority weight of the components that affect employee performance. From the calculation by AHP method can be obtained by order of priority as follows: The first is the human resources with priority weight 0.558. The second is working environmental conditions with priority weight 0.312. Last is managerial with priority weight 0.131. Thus the factors that require attention and consideration of the company to increase work performance is a factor of human resource with the greatest priority weight.
\end{abstract}

Key word : analytical hierarchy process, employee performance, human resources managerial, work environment.

\begin{abstract}
Abstrak.
Kinerja karyawan adalah hasil kerja yang dicapai atau hasil yang telah dilakukan atau dikerjakan oleh seorang karyawan dalam tugas-tugas yang dibebankan kepada karyawan. Masalahnya adalah bobot prioritas faktor dan subfaktor untuk mendapatkan solusi terlebih dahulu sesuai dengan urutan prioritas. Dalam penelitian ini data yang dikumpulkan dilakukan dengan observasi langsung, wawancara, kuesioner dan sastra. Setelah data diproses untuk menentukan bobot prioritas dari komponen yang mempengaruhi kinerja karyawan. Dari perhitungan dengan metode AHP dapat diperoleh dengan urutan prioritas sebagai berikut: Prioritas pertama dari sumber daya manusia bobot prioritas 0,558. Prioritas kedua kondisi lingkungan bekerja dengan bobot prioritas 0,312. prioritas manajerial dan terakhir adalah bobot prioritas 0,131. Dengan demikian faktor-faktor yang memerlukan perhatian dan pertimbangan perusahaan untuk meningkatkan kinerja adalah faktor sumber daya manusia dengan perolehan berat prioritas terbesar.
\end{abstract}

Kata kunci : analytical hierarchy process, kinerja karyawan, human resource managerial, lingkungan kerja.

\section{Pendahuluan}

Perubahan teknologi yang semakin cepat dan meningkatnya kebutuhan organisasi yang fleksibel mengakibatkan pergeseran penting terhadap fungsi manajemen sumber daya

\footnotetext{
${ }^{1}$ Krisnadhi Hariyanto, Program Studi Teknik Industri, Fakultas Teknik, Universitas Wijaya Putra Surabaya, J1. Raya Benowo No. 1-3, Surabaya - 60197, Indonesia (email: krisnadi@uwp.ac.id)

${ }^{2}$ Eko Budi Satoto, Program Studi Teknik Industri, Fakultas Teknik, Universitas Wijaya Putra Surabaya, Jl. Raya Benowo No. 1-3, Surabaya - 60197, Indonesia (email: ekobudisatoto@yahoo.co.id)
}

Diajukan: 22-11-2015

Diperbaiki: 25-04-2016 manusia. Perubahan teknologi, khususnya penggunaan teknologi canggih dan komputer memberi pengaruh terhadap pengetahuan, keahlian dan perilaku yang dibutuhkan ditempat kerja (Nasibu, 2009). Kondisi tersebut meningkatkan permintaan terhadap ketrampilan baru yang sesuai dengan perkembangan teknologi yang paling mutakhir. Meningkatnya kebutuhan organisasi yang fleksibel mendorong perusahaan untuk melakukan perubahan-perubahan strategi, seperti globalisasi, desentralisasi, serta diversifikasi, yang membawa akibat pada perubahan jalur karir, kompetensi inti, dan peluang karir.

Kompetisi global dan perubahan-perubahan kondisi ekonomi menyebabkan banyak perusahaan dari bermacam-macam ukuran melakukan langkah restrukturisasi. Perubahan- 
perubahan ini menunjukan bahwa perusahaan dewasa ini harus mengetahui bagaimana mendayagunakan karyawan secara baik pada semua jenjang dalam perusahaan (Winkel, 2005). Orang-orang yang cakap harus tersedia untuk mengisi pekerjaan-pekerjaan baru, lebih besar dan lebih canggih secara teknologi. Hal ini berarti bahwa kunci untuk memenangkan komitmen karyawan bagi perusahaan adalah menawarkan kepada karyawan suatu kesempatan untuk memiliki dan mengisi sebuah karir yang berhasil.

Prestasi kerja ini dianalisa dengan satu variabel dependen yaitu prestasi kerja karyawan non staf. Tujuannya agar tercapai timbal balik yang baik antara karyawan staf dan karyawan non staf. Penelitian ini terdiri dari dua kategori responden yaitu responden staf dan responden non staf. Karyawan staf adalah karyawan yang bekerja di kantor dan memiliki tugas dan tanggung jawab tertentu (tenaga kerja non pabrik). Sedangkan karyawan non staf adalah karyawan yang tidak menduduki suatu jabatan tertentu dan tugasnya untuk melaksanakan tugas harian operasional / tenaga kerja pabrik (Mulyadi, 2006).

Metode pengambilan sampel yang peneliti gunakan adalah random sampling satu kelompok sampel (karyawan non staf). Pengolahan data dilakukan dengan metode Analytical Hierarchy Process (AHP) untuk mencari bobot masingmasing faktor yang ada dalam hirarki.

\section{Prestasi kerja}

Keberhasilan suatu perusahaan hanya dapat dicapai dengan usaha dan kualitas sumber daya manusia yaitu tenaga kerja atau karyawannya. Usaha-usaha yang dilakukan berbentuk pengembangan manajemen, perbaikan sistem kerja dan usaha-usaha yang mengadakan alih teknologi baik yang menengah maupun teknologi tinggi. Di samping itu, perusahaan juga perlu meningkatkan kualitas sumber daya manusia yang dimilikinya. Untuk mengetahui adanya peningkatan kualitas sumber daya manusia yang dimilikinya, maka pihak perusahaan perlu menentukan faktor-faktor yang mempengaruhi prestasi kerja karyawannya, kemudian perusahaan melakukan penilaian terhadap prestasi kerja tersebut. Penilaian prestasi kerja ini merupakan pengawasan terhadap kualitas sumber daya manusia (Rochmasari, dkk, 2010).

Pengertian penilaian prestasi kerja adalah suatu sistem yang digunakan untuk menilai dan mengetahui sejauh mana karyawan telah melaksanakan pekerjaannya masing-masing secara keseluruhan. Pekerjaan keseluruhan menyangkut kemampuan kerja, disiplin, hubungan kerja, prakarsa, kepemimpinan, dan hal-hal khusus sesuai dengan bidang pekerjaannya (Suprihanto, 2006).

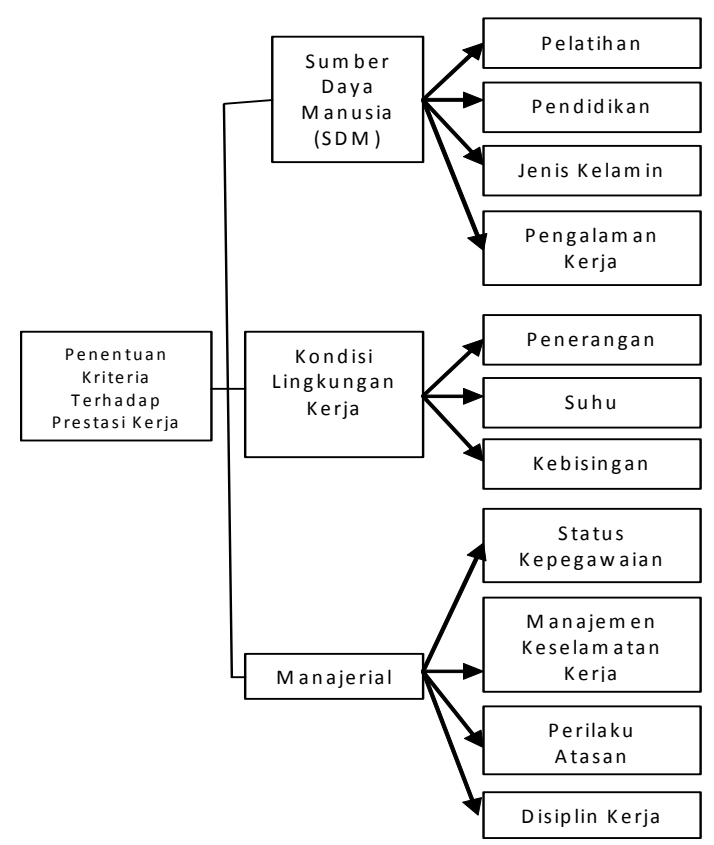

Gambar 1. Kerangka kriteria prestasi kerja

Faktor tenaga kerja tidak dapat diabaikan, bahkan merupakan faktor kunci. Sebab kesalahan dan kekeliruan yang terjadi dapat menyebabkan hambatan-hambatan yang serius, bahkan dapat menyebabkan kegagalan total. Dalam perhitungan dengan metode AHP penyusunan suatu masalah ke dalam struktur hirarki merupakan hal yang sangat penting. Dalam penyusunan hirarki ini, peneliti mengadakan wawancara dengan pihak perusahaan mengenai hal-hal yang berkaitan dengan prestasi kerja terutama faktor dan sub faktor yang berpengaruh dari prestasi kerja sehingga dapat diketahui seberapa besar bobot prioritas faktor dan sub faktor tersebut mempengaruhi prestasi kerja (Handoko, 2006).

Semua informasi dari kriteria ini terdiri dari: (1) faktor sumber daya manusia (SDM) terdiri 
dari sub faktor: pelatihan, pendidikan, jenis kelamin, dan pengalaman kerja, (2) faktor kondisi lingkungan kerja, terdiri dari sub faktor: penerangan, suhu, dan kebisingan, dan (3) faktor manajerial, terdiri dari sub faktor: status kepegawaian, manajemen keselamatan kerja, perilaku atasan, dan disiplin kerja.

\section{Penerapan AHP}

Tahapan proses pengambilan keputusan dengan menggunakan AHP adalah (Saaty, 2003): (1) penstrukturan masalah ke dalam suatu hirarki, sehingga masalah yang kompleks menjadi lebih mudah diselesaikan, (2) mensintesakan hasil, dimana pendapat-pendapat yang telah diberikan angka numerik menjadi masukan untuk diolah melalui suatu prosedur tertentu menjadi bobot antar faktor, (3) formulasi matematis, dalam suatu subsistem operasi terdapat $\mathrm{n}$ elemen operasi, yaitu elemen-elemen operasi $\mathrm{A}_{1}, \mathrm{~A}_{2}$, $\ldots, A_{n}$, maka hasil perbandingan secara berpasangan elemen-elemen operasi tersebut akan membentuk matrik perbandingan.

Penggunaan metode proses analisis hirarki ini memungkinkan untuk memperoleh penilaian yang didasarkan pada penilaian dengan menggunakan kuesioner. Ada beberapa hal yang harus diperhatikan di sini, yaitu:

1. Jika suatu kelompok ikut berpartisipasi dalam proses penilaian, seluruh anggota kelompok itu sedapat mungkin diusahakan untuk dapat mencapai koensinsus dalam penilaiannya. Tetapi jika konsensus tersebut tidak dapat dicapai, dapat digunakan geometric mean dari penilaian mereka.

2. Dilakukan perhitungan geometric mean, tentunya beralasan yaitu karena ciri "reciprocality" dari matriks yang digunakan dalam proses analisis hirarki ini harus tetap dipertahankan.

3. Geometric mean inilah yang dapat menghitung nilai rata-rata dari penilaian perbandingan berpasangan, dengan tetap mempertahankan ciri "reciprocality" dari matriks tadi.

Adapun rumus dari geometric mean tersebut adalah:

Tabel 1. Skala perbandingan berpasangan

\begin{tabular}{|c|c|c|}
\hline $\begin{array}{c}\text { Intensitas } \\
\text { Kepentingan }\end{array}$ & Definisi Verbal & Penjelasan \\
\hline 1 & Kedua elemen sama pentingnya. & $\begin{array}{l}\text { Penilaian satu elemen yang } \\
\text { dibandingkan dengan elemen } \\
\text { lainnya adalah sama. }\end{array}$ \\
\hline 3 & $\begin{array}{l}\text { Satu elemen lebih lemah tingkat } \\
\text { kepentingannya dibadnibgkan } \\
\text { dengan elemen lainnya. }\end{array}$ & $\begin{array}{l}\text { Penilaian sedikit memihak pada } \\
\text { sebuah elemen dibandingkan } \\
\text { elemen lainnya. }\end{array}$ \\
\hline 5 & $\begin{array}{l}\text { Satu elemen lebih essensial atau } \\
\text { mempunyai tingkat kepentingan } \\
\text { yang cukup kuat dibandingkan } \\
\text { terhadap elemen lainnya. }\end{array}$ & $\begin{array}{l}\text { Penilaian secara kuat memihak } \\
\text { pada sebuah elemen dibandingkan } \\
\text { elemen lainnya. }\end{array}$ \\
\hline 7 & $\begin{array}{l}\text { Satu elemen menunjukkan tingkat } \\
\text { kepentingan yang sangat kuat } \\
\text { dibandingkan terhadap elemen } \\
\text { lainnya. }\end{array}$ & $\begin{array}{l}\text { Sebuah elemen secara kuat disukai } \\
\text { dan mendominasi terhadap elemen } \\
\text { lainnya. }\end{array}$ \\
\hline 9 & $\begin{array}{l}\text { Salah satu elemen menunjukkan } \\
\text { tingkat kepentingan yang mutlak } \\
\text { lebih tinggi terhadap elemen } \\
\text { lainnya. }\end{array}$ & $\begin{array}{l}\text { Bukti bahwa suatu elemen wajib } \\
\text { ada dibandingkan elemen lainnya. }\end{array}$ \\
\hline $2,4,6,8$ & $\begin{array}{l}\text { Nilai-nilai tengah diantara dua } \\
\text { pendapat yang berdampingan. }\end{array}$ & $\begin{array}{l}\text { Nilai-nilai yang diberikan bila } \\
\text { diperlukan suatu kompromi. }\end{array}$ \\
\hline $\begin{array}{l}\text { Kebalikan dari } \\
\text { nilai di atas. }\end{array}$ & \multicolumn{2}{|c|}{$\begin{array}{l}\text { Jika elemen i memperoleh salah satu nilai dari tabel nilai di atas pada saat } \\
\text { dibandingkan dengan elemen } \mathrm{j} \text {, maka elemen j memiliki nilai } \\
\text { kebalikkannya bila dibandingkan dengan nilai i. }\end{array}$} \\
\hline
\end{tabular}




$$
G M=\sqrt[n]{X_{1} \cdot X_{2} \cdot X_{3} \ldots \cdot X_{n}}
$$

dimana:

$$
\begin{aligned}
& G M=\text { Geometric Mean } \\
& X_{1}, . ., X_{n}=\text { bobot penilaian ke } 1,2,3, \ldots, n . \\
& n \quad=\text { jumlah ordo }
\end{aligned}
$$

Setelah bobot telah diperoleh dan nilai berdasarkan penilaian yang telah ditetapkan berdasarkan kinerja yang ditunjukkan karyawan dalam menyelesaikan pekerjaannya, maka langkah yang dilakukan selanjutnya adalah mencari skor dan nilai prestasi kinerja akhir dari seorang karyawan.

Tabel 2. Penentuan nilai prestasi kerja karyawan

\begin{tabular}{|c|c|c|c|c|}
\hline No. & $\begin{array}{c}\text { Faktor } \\
\text { Penilaian }\end{array}$ & Bobot & Nilai & Skor \\
\hline 1. & & & & \\
\hline 2. & & & & \\
\hline 3. & & & & \\
\hline 4. & & & & \\
\hline 5. & & & & \\
\hline 6. & \multicolumn{5}{|c|}{ Nilai Prestasi Kinerja } & \\
\hline \multicolumn{5}{|c|}{} \\
\hline
\end{tabular}

Tiga prinsip memecahkan persoalan dengan AHP, yaitu prinsip menyusun hirarki, prinsip menentukan prioritas, dan prinsip mengukur konsistensi (Kusrini, 2007). Proses pengambilan keputusan pada dasarnya memilih suatu alternatif. Peralatan utama AHP adalah sebuah hirarki fungsional dengan input utamanya persepsi manusia.

Dalam menyelesaikan permasalahan dengan AHP ada beberapa prinsip yang harus dipahami, yaitu (Permadi \& Endang, 2008; Kusumadewi, dkk, 2010): (a) membuat hirarki, (b) penilaian faktor dan alternative, (c) menentukan prioritas, dan (d) mengukur konsistensi.

Langkah penyelesaian dengan AHP:

a. Menentukan jenis-jenis kriteria yang akan menjadi persyaratan penilaian.

b. Menyusun kriteria-kriteria tersebut dalam bentuk matriks berpasangan.

c. Menjumlah matriks kolom.

d. Menghitung nilai elemen kolom kriteria dengan rumus masing-masing elemen kolom dibagi dengan jumlah matriks kolom.

e. Menghitung nilai prioritas kriteria dengan rumus menjumlah matriks baris hasil langkah ke 4 dan hasilnya 5 dibagi dengan jumlah kriteria.

f. Menentukan alternatif-alternatif yang menjadi pilihan.

g. Menyusun alternatif-alternatif yang telah ditentukan dalam bentuk matriks berpasangan untuk masing-masing kriteria. Sehingga ada sebanyak $n$ buah matriks berpasangan antar alternatif.

h. Masing-masing matriks berpasangan antar alternatif sebanyak $n$ buah matriks, masingmasing matriksnya dijumlah per kolomnya.

i. Menghitung nilai prioritas alternatif masingmasing matriks berpasangan antar alternatif dengan rumus seperti langkah 4 dan 5 .

j. Menguji konsistensi setiap matriks berpasangan antar alternatif dengan rumus masing-masing elemen matriks berpasangan pada langkah 2 dikalikan dengan nilai prioritas kriteria. Hasilnya masing-masing baris dijumlah, kemudian hasilnya dibagi dengan masing-masing nilai prioritas kriteria sebanyak $\alpha_{1}, \alpha_{2}, \ldots, \alpha_{n}$.

k. Menghitung $\lambda_{\max }$ dengan rumus:

$$
\lambda_{\max }=\sum \frac{\alpha_{i}}{n}
$$

1. Menghitung consistency index (CI) dengan rumus:

$$
C I=\frac{\lambda_{\max }}{(n-1)}
$$

$\mathrm{m}$. Menghitung consistency ratio (CR) dengan rumus:

$$
C R=\frac{C I}{R C}
$$

dimana $\mathrm{RC}$ adalah nilai yang berasal dari tabel random seperti Tabel 3.

Tabel 3. Nilai RC

\begin{tabular}{cccccc}
\hline $\mathrm{n}$ & 1 & 2 & 3 & 4 & 5 \\
$\mathrm{RC}$ & 0,0 & 0,00 & 0,58 & 0,90 & 1,12 \\
\hline $\mathrm{n}$ & 6 & 7 & 8 & 9 & 10 \\
$\mathrm{RC}$ & 1,24 & 1,32 & 1,41 & 1,45 & 1,49 \\
\hline \multicolumn{2}{l}{ Sumber : Saaty, 2003} & & &
\end{tabular}

- Jika $\mathrm{CR}<0,1$, maka nilai perbandingan berpasangan pada matriks kriteria yang diberikan konsisten.

- Jika CR > 0,1, maka maka nilai perbandingan berpasangan pada matriks kriteria yang diberikan tidak konsisten.

- Sehingga jika tidak konsisten, maka pengisian nilai-nilai pada matriks berpasangan pada unsur kriteria maupun alternatif harus diulang. 
n. Menyusun matriks baris antara alternatif versus kriteria yang isinya hasil perhitungan proses langkah 7, 8 dan 9.

o. Hasil akhirnya berupa prioritas global sebagai nilai yang digunakan oleh pengambil keputusan berdasarkan skor yang tertinggi.

\section{Metodologi}

Metode penelitian terdiri dari :

a. Pengujian konsistensi data, yang dilakukan dengan batasan nilai consistency ratio $(C R)$. Apabila koesioner mempunyai nilai lebih besar dari 0,1, maka perhitungan harus diulang/direvisi.

b. Untuk mendapatkan nilai dari bermacammacam penilaian, maka harus menyatukan pertimbangan dengan perhitungan rata-rata geometrik.

c. Buat matriks perbandingan (faktor dan subfaktor), kemudian ubah dalam angka desimal.

d. Kalikan matriks perbandingan tersebut dengan matriks bobot prioritas.

e. Bagi setiap elemen matriks hasil dengan elemen matriks bobot prioritas.

f. Hitung nilai maximum eigenvalue (ME).

g. Hitung nilai consistency index $(\mathrm{CI})$.

h. Pengujian consistency ratio (CR).

\section{HASIL DAN PEMBAHASAN}

\section{Data dan rasio konsistensi data}

Dari daftar kuesioner yang telah terisi kemudian dilakukan pengujian untuk menilai konsistensi jawaban yang diberikan responden. Kuesioner yang memiliki consistency ratio lebih dari 0,1 akan digugurkan dan tidak akan digunakan untuk pengolahan selanjutnya. Sebelum menentukan nilai consistency ratio terlebih dahulu ditentukan nilai eigen vector dan eigen value.

Dengan melakukan penilaian relatif pada setiap sel yaitu dengan cara setiap sel dibagi dengan jumlah pada setiap kolomnya maka akan diperoleh nilai relatif per sel. Akhirnya pada setiap sel atribut atau faktor secara horizontal dijumlahkan dan dicari prioritasnya. Hubungan preferensi yang dikenakan pada 2 elemen tidak mempunyai masalah konsistensi relasi sehingga tidak diperlukan pengujian konsistensi matriks perbandingan.

Dengan cara yang sama ditentukan pula perhitungan bobot prioritas keseluruhan responden, yaitu sejumlah 5 responden pada perbandingan antar atribut. Selanjutnya jawaban responden untuk sub-atribut kepuasan kerja diolah dengan cara yang sama (lihat Tabel 4 sampai Tabel 7).

\section{Bobot prioritas}

Bobot prioritas menunjukkan besarnya kontribusi masing-masing atribut dan perhitungan bobot prioritas diambil dari data jawaban kuesioner responden yang telah dicari dengan perhitungan AHP. Penilaian dilakukan oleh beberapa partisipan yang menghasilkan pendapat yang berbeda.

AHP hanya membutuhkan satu jawaban untuk satu matriks perbandingan sehingga semua jawaban dari partisipan harus dirata-ratakan dan untuk mengatasi hal ini digunakan perataan dengan geometric mean. Dari perhitungan tersebut akan diketahui atribut atau sub atribut yang mempunyai nilai kemungkinan paling besar untuk diprioritaskan sebagai pertimbangan dalam menentukan bobot tiap kemampuan kerja maupun kriteria kinerja untuk melakukan penilaian kinerja karyawan (lihat Tabel 8).

Tabel 4. Matriks perbandingan berpasangan untuk prestasi kerja

\begin{tabular}{|c|c|c|c|}
\hline \multicolumn{4}{|l|}{ Responden 1} \\
\hline PK & MNJ & LGK & SDM \\
\hline MNJ & 1 & $1 / 3$ & $1 / 4$ \\
\hline LGK & 3 & 1 & $1 / 3$ \\
\hline SDM & 4 & 3 & 1 \\
\hline \multicolumn{4}{|l|}{ Responden 2} \\
\hline PK & MNJ & LGK & SDM \\
\hline MNJ & 1 & $1 / 4$ & $1 / 3$ \\
\hline LGK & 4 & 1 & $1 / 2$ \\
\hline SDM & 3 & 2 & 1 \\
\hline \multicolumn{4}{|l|}{ Responden 3} \\
\hline PK & MNJ & LGK & SDM \\
\hline MNJ & 1 & 1 & $1 / 2$ \\
\hline LGK & 1 & 1 & $1 / 2$ \\
\hline SDM & 2 & 2 & 1 \\
\hline \multicolumn{4}{|l|}{ Responden 4} \\
\hline PK & MNJ & LGK & SDM \\
\hline MNJ & 1 & $1 / 2$ & $1 / 2$ \\
\hline LGK & 2 & 1 & $1 / 2$ \\
\hline SDM & 2 & 2 & 1 \\
\hline \multicolumn{4}{|l|}{ Responden 5} \\
\hline PK & MNJ & LGK & SDM \\
\hline MNJ & 1 & $1 / 3$ & $1 / 2$ \\
\hline LGK & 3 & 1 & 1 \\
\hline SDM & 2 & 1 & 1 \\
\hline
\end{tabular}


Tabel 5. Matriks perbandingan berpasangan untuk lingkungan kerja

\begin{tabular}{|c|c|c|c|}
\hline \multicolumn{4}{|l|}{ Responden 1} \\
\hline LGK & PNRG & SUHU & KBSG \\
\hline PNRG & 1 & 3 & 4 \\
\hline SUHU & $1 / 3$ & 1 & 2 \\
\hline BSG & $1 / 4$ & $1 / 2$ & 1 \\
\hline \multicolumn{4}{|l|}{ Responden 2} \\
\hline LGK & PNRG & SUHU & KBSG \\
\hline PNRG & 1 & $1 / 2$ & $1 / 3$ \\
\hline SUHU & 2 & 1 & 4 \\
\hline KBSG & 3 & $1 / 4$ & 1 \\
\hline \multicolumn{4}{|l|}{ Responden 3} \\
\hline LGK & PNRG & SUHU & KBSG \\
\hline PNRG & 1 & $1 / 5$ & $1 / 3$ \\
\hline SUHU & 5 & 1 & 3 \\
\hline KBSG & 3 & $1 / 3$ & 1 \\
\hline \multicolumn{4}{|l|}{ Responden 4} \\
\hline LGK & PNRG & SUHU & KBSG \\
\hline PNRG & 1 & 1 & 2 \\
\hline SUHU & 1 & 1 & $1 / 3$ \\
\hline KBSG & $1 / 2$ & 3 & 1 \\
\hline \multicolumn{4}{|l|}{ Responden 5} \\
\hline LGK & PNRG & SUHU & KBSG \\
\hline PNRG & 1 & 2 & $1 / 7$ \\
\hline SUHU & $1 / 2$ & 1 & 4 \\
\hline KBSG & 7 & $1 / 4$ & 1 \\
\hline
\end{tabular}

LGK= lingkungan kerja, $\mathrm{PNRG}=$ penerangan,

SUHU= suhu ruang, KBSG= kebisingan

Tabel 6. Matriks perbandingan berpasangan untuk sumber daya manusia

\begin{tabular}{|c|c|c|c|c|}
\hline \multicolumn{5}{|l|}{ Responden 1} \\
\hline SDM & PLTH & PDDK & JKLM & PGLM \\
\hline PLTH & 1 & 4 & 1 & 5 \\
\hline PDDK & $1 / 4$ & 1 & 1 & 3 \\
\hline JKLM & 1 & 1 & 1 & $1 / 3$ \\
\hline PGLM & $1 / 5$ & $1 / 3$ & 3 & 1 \\
\hline \multicolumn{5}{|l|}{ Responden 2} \\
\hline SDM & PLTH & PDDK & JKLM & PGLM \\
\hline PLTH & 1 & 3 & 1 & 5 \\
\hline PDDK & $1 / 4$ & 1 & 1 & 3 \\
\hline JKLM & 1 & 1 & 1 & $1 / 3$ \\
\hline PGLM & $1 / 5$ & $1 / 5$ & $1 / 7$ & 1 \\
\hline \multicolumn{5}{|l|}{ Responden 3} \\
\hline SDM & PLTH & PDDK & JKLM & PGLM \\
\hline PLTH & 1 & 3 & 2 & 3 \\
\hline PDDK & $1 / 3$ & 1 & $1 / 2$ & 2 \\
\hline JKLM & $1 / 2$ & 2 & 1 & 2 \\
\hline PGLM & $1 / 3$ & $1 / 2$ & $1 / 2$ & 1 \\
\hline \multicolumn{5}{|l|}{ Responden 4} \\
\hline SDM & PLTH & PDDK & JKLM & PGLM \\
\hline PLTH & 1 & 2 & 3 & 3 \\
\hline PDDK & $1 / 2$ & 1 & 3 & 2 \\
\hline JKLM & $1 / 3$ & $1 / 3$ & 1 & 3 \\
\hline PGLM & $1 / 3$ & $1 / 2$ & $1 / 3$ & 1 \\
\hline \multicolumn{5}{|l|}{ Responden 5} \\
\hline SDM & PLTH & PDDK & JKLM & PGLM \\
\hline PLTH & 1 & 1 & $1 / 5$ & 1 \\
\hline PDDK & 1 & 1 & $1 / 5$ & $1 / 4$ \\
\hline JKLM & 5 & 5 & 1 & 5 \\
\hline PGLM & 1 & 4 & $1 / 5$ & 1 \\
\hline
\end{tabular}

$\mathrm{SDM}=$ sumber daya manusia, $\mathrm{PLTH}=$ pelatihan, $\mathrm{PDDK}=$
pendidikan, $\mathrm{JKLM}=$ jenis kelamin, $\mathrm{PGLM}=$ pengalaman kerja
Tabel 7. Matriks perbandingan berpasangan untuk manajerial

\begin{tabular}{|c|c|c|c|c|}
\hline \multicolumn{5}{|l|}{ Responden 1} \\
\hline $\mathrm{MNJ}$ & STKP & MKKK & PLKA & DSPK \\
\hline STKP & 1 & 2 & 2 & 2 \\
\hline MKKK & $1 / 2$ & 1 & $1 / 2$ & 1 \\
\hline PLKA & $1 / 2$ & 2 & 1 & $1 / 2$ \\
\hline DSPK & $1 / 2$ & 1 & 2 & 1 \\
\hline \multicolumn{5}{|l|}{ Responden 2} \\
\hline MNJ & STKP & MKKK & PLKA & DSPK \\
\hline STKP & 1 & $1 / 4$ & $1 / 2$ & 2 \\
\hline MKKK & 4 & 1 & $1 / 3$ & 1 \\
\hline PLKA & 2 & 3 & 1 & 4 \\
\hline DSPK & $1 / 2$ & 1 & $1 / 4$ & 1 \\
\hline \multicolumn{5}{|l|}{ Responden 3} \\
\hline MNJ & STKP & MKKK & PLKA & DSPK \\
\hline STKP & 1 & $1 / 2$ & 4 & $1 / 4$ \\
\hline MKKK & 2 & 1 & 4 & $1 / 4$ \\
\hline PLKA & $1 / 4$ & $1 / 4$ & 1 & $1 / 5$ \\
\hline DSPK & 4 & 4 & 5 & 1 \\
\hline \multicolumn{5}{|l|}{ Responden 4} \\
\hline MNJ & STKP & MKKK & PLKA & DSPK \\
\hline STKP & 1 & $1 / 3$ & $1 / 2$ & $1 / 2$ \\
\hline MKKK & 3 & 1 & 3 & 2 \\
\hline PLKA & 2 & $1 / 3$ & 1 & $1 / 2$ \\
\hline DSPK & 4 & $1 / 2$ & 2 & 1 \\
\hline \multicolumn{5}{|l|}{ Responden 5} \\
\hline MNJ & STKP & MKKK & PLKA & DSPK \\
\hline STKP & 1 & 2 & 2 & 2 \\
\hline MKKK & $1 / 2$ & 1 & $1 / 5$ & $1 / 4$ \\
\hline PLKA & $1 / 2$ & 5 & 1 & $1 / 4$ \\
\hline DSPK & $1 / 2$ & 4 & 2 & 1 \\
\hline
\end{tabular}

$\mathrm{MNJ}=$ manajerial, $\mathrm{STKP}=$ status kepegawaian,

MKKK= manajemen kesehatan dan keselamatan kerja, $\mathrm{PLKA}=$ perilaku atasan, $\mathrm{DSPK}=$ disiplin kerja

Tabel 8. Hasil akhir AHP

\begin{tabular}{|c|c|c|c|c|}
\hline Tujuan & Faktor & Bobot & Sub Faktor & Bobot \\
\hline \multirow{11}{*}{$\begin{array}{l}\text { Prestasi } \\
\text { Kerja } \\
\text { Karyawan }\end{array}$} & \multirow{4}{*}{$\begin{array}{l}\text { Sumber } \\
\text { Daya } \\
\text { Manusia }\end{array}$} & \multirow{4}{*}{0,558} & Pelatihan & 0,208 \\
\hline & & & Pendidikan & 0,103 \\
\hline & & & $\begin{array}{l}\text { Jenis } \\
\text { Kelamin }\end{array}$ & 0,179 \\
\hline & & & $\begin{array}{l}\text { Pengalaman } \\
\text { Kerja }\end{array}$ & 0,081 \\
\hline & \multirow{3}{*}{$\begin{array}{l}\text { Kondisi } \\
\text { Lingkungan } \\
\text { Kerja }\end{array}$} & \multirow{3}{*}{0,312} & Penerangan & 0,087 \\
\hline & & & Suhu & 0,132 \\
\hline & & & Kebisingan & 0,093 \\
\hline & \multirow{4}{*}{ Manajerial } & \multirow{4}{*}{0,131} & $\begin{array}{l}\text { Manajemen } \\
\text { Keselamatan } \\
\text { Kerja }\end{array}$ & 0,035 \\
\hline & & & $\begin{array}{l}\text { Status } \\
\text { Kepegawaian }\end{array}$ & 0,034 \\
\hline & & & $\begin{array}{l}\text { Disiplin } \\
\text { Kerja } \\
\end{array}$ & 0,033 \\
\hline & & & $\begin{array}{l}\text { Perilaku } \\
\text { Atasan }\end{array}$ & 0,028 \\
\hline
\end{tabular}

Hasil hirarki pembobotan dapat dilihat pada Tabel 8. Pembobotan yang dilakukan oleh responden ahli menghasilkan nilai yang berbeda pada tiap kriteria perusahaan berdasarkan bobot tertinggi sampai nilai bobot terendah adalah 
sumber daya manusia atau SDM $(0,558)$, kondisi lingkungan kerja $(0,312)$, dan manajerial $(0,131)$. Sumber daya manusia (SDM) memiliki nilai bobot tertinggi karena menurut responden ahli SDM akan mempengaruhi sikap, persepsi, dan juga motivasi bagi karyawan dalam memandang suatu tugas. Organisasi cenderung memilih sikap SDM karena berhubungan erat dengan kinerja di beberapa pekerjaan dan organisasi. Hubungan manajerial memperoleh nilai bobot terkecil karena menurut responden ahli kriteria ini dianggap tidak membutuhkan kriteria khusus dalam penerapannya dilapangan karena sejauh ini manajerial yang ada di perusahaan sudah terjalin dengan baik dan profesional.

Tabel 8 menunjukkan bahwa bobot subkriteria terbesar pada kriteria pelatihan diperoleh oleh subkriteria pelatihan dimana bobot yang diperoleh sebesar 0,208. Menurut responden ahli, pelatihan yang baik harus dimiliki oleh setiap karyawan non staf, karena dengan pelatihan yang baik dan teratur sangat penting dimiliki oleh setiap karyawan agar pekerjaannya dapat berjalan dengan baik. Pengalaman kerja memiliki nilai bobot terkecil pada subkriteria pelatihan sebesar 0,081, dengan kata lain menurut responden ahli pada saat proses pelatihan terdapat tes yang harus dilalui oleh karyawan. Salah satunya adalah tes pengalaman kerja, sehingga karyawan yang dinyatakan lulus pada tes tersebut merupakan karyawan yang mempunyai skill dan kemampuan sesuai dengan pekerjaannya.

Nilai bobot sub kriteria terbesar dalam kondisi lingkungan kerja diperoleh oleh subkriteria suhu dimana nilai yang diperoleh sebesar 0,132 . Beberapa faktor suhu yang mempengaruhi kinerja antara lain kemampuan karyawan untuk menyesuaikan diri terhadap perubahan perilaku orang lain dalam suatu keadaan tertentu. Nilai bobot sub kriteria terkecil yakni penerangan, dimana nilai bobot yang diperoleh hanya 0,087 . Menurut responden ahli penerangan merupakan penunjang dalam menyelesaikan tugas dan juga hasil akhir dari penyelesaian tugas, sehingga menurut responden ahli kondisi lingkungan mendapatkan bobot terkecil dibandingkan dengan subkriteria lain dalam satu lingkup kriteria kondisi lingkungan.

Nilai bobot sub kriteria terbesar dalam kriteria manajerial, diperoleh sub kriteria manajemen keselamatan kerja dengan bobot sebesar 0,035.
Sub kriteria ini mendapatkan nilai bobot terbesar karena menurut responden ahli manajemen keselamatan kerja karyawan sangat mempengaruhi hasil tugas, sehingga setiap karyawan dituntut agar mampu dan memiliki manajemen keselamatan kerja dalam melaksanakan tugas agar tujuan dari perusahaan dapat tercapai dengan baik. Nilai bobot terkecil diperoleh oleh sub kriteria perilaku atasan dengan nilai 0,028 . Sub kriteria ini dinilai memiliki nilai bobot terkecil karena jika subkriteria yang memiliki nilai diatasnya sudah terlaksana dengan baik maka kecepatan penyelesaian tugas mengikuti.

\section{Pembahasan}

Berdasarkan hasil perhitungan bobot prioritas atribut terhadap masalah penilaian kinerja karyawan, diperoleh nilai bobot prioritas masingmasing kinerja secara berurutan sebagai berikut :

1. Faktor sumber daya manusia memiliki bobot prioritas sebesar 0,558 .

2. Faktor kondisi lingkungan kerja memiliki bobot prioritas sebesar 0,312.

3. Faktor manajerial memiliki bobot prioritas sebesar 0,131.

Faktor-faktor yang mempengaruhi SDM (individu) adalah faktor pelatihan dengan bobot sebesar 0,208. Faktor yang kedua adalah jenis kelamin dengan bobot sebesar 0,179 . Faktor yang ketiga adalah Pendidikan dengan bobot sebesar 0,103. dan faktor yang terakir adalah faktor pengalaman kerja dengan bobot sebesar 0,081.

Faktor-faktor yang mempengaruhi faktor dari kondisi lingkungan kerja adalah yang pertama yaitu faktor suhu dengan bobot sebesar 0,132. Faktor yang kedua adalah faktor kebisingan dengan bobot sebesar 0,093.

Faktor-faktor yang mempengaruhi faktor manajerial adalah faktor manajemen kesehatan dan keselamatan kerja dengan bobot sebesar 0,035 . Faktor status kepegawaian dengan $\mathrm{n}$ i 1 a i bobot sebesar 0,034 dan faktor disiplin kerja dengan nilai bobot sebesar 0,033. Dan faktor yang terakhir adalah faktor perilaku atasan dengan bobot sebesar 0,028.

Dari hasil perhitungan bobot prioritas tersebut, dapat diketahui bahwa atribut yang paling berpengaruh terhadap penilaian kinerja karyawan adalah faktor sumber daya manusia (pelatihan) dengan bobot prioritas sebesar 0,208, dan yang 
terakhir adalah faktor manajerial (perilaku atasan) dengan bobot prioritas sebesar 0,028.

Atribut sumber daya manusia dipilih sebagai prioritas pertama dalam penilaian kinerja karyawan dikarenakan responden atau para penilai memiliki satu pemikiran bahwa sumber daya manusia merupakan faktor utama yang harus dimiliki karyawan dalam bekerja dan menyelesaikan tugasnya. Dari hasil perhitungan bobot prioritas tersebut, dapat diketahui bahwa sub atribut yang paling berpengaruh terhadap atribut penilaian kinerja karyawan adalah kriteria pelatihan sebesar 0,208, kriteria suhu sebesar 0,132 , dan kriteria manajemen keselamatan kerja sebesar 0,035.

Dari sini dapat diartikan bahwa untuk mendapatkan kualitas individu yang baik, maka dibutuhkan pelatihan yang baik dan berkualitas. Kemudian faktor kondisi lingkungan kerja juga berpengaruh terutama pada suhu lingkungan kerja, karena manusia dapat bekerja dengan efektif pada suhu normal, produktifitas kerja manusia akan mencapai tingkat yang paling tinggi pada temperatur sekitar antara $24-27^{\circ} \mathrm{C}$. Kemudian faktor manajerial juga berpengaruh terutama dari kebijakan-kebijakan yang dibuat oleh atasan terutama mengenai disiplin kerja, ini harus mudah untuk dipahami dan dilaksanakan.

\section{SIMPULAN}

Hasil penelitian pembahasan di atas, dapat diambil simpulan sebagai berikut:

1. Prestasi kerja karyawan dipengaruhi oleh kualitas individu karyawan, kondisi lingkungan kerja, dan proses manajerial yang dilakukan.

2. Hal paling penting untuk meningkatkan prestasi kerja adalah dengan memberikan pelatihan kepada karyawan.

3. Hal yang paling tidak memberikan pengaruh untuk peningkatan prestasi kerja karyawan adalah perilaku atasan.

\section{DAFTAR PUSTAKA}

Handoko, T.H. (2006). Manajemen Personalia dan Sumber Daya Manusia. Yogyakarta: BPFE UGM.

Kusrini. (2007). Konsep dan Aplikasi Sistem Pendukung Keputusan. Yogyakarta: Andi.
Kusumadewi, S.; Purnomo, H. (2010). Aplikasi Logika Fuzzy Untuk Pendukung Keputusan. Edisi 2. Yogyakarta: Graha Ilmu.

Mulyadi. (2006). Auditing Buku I. Jakarta: Salemba Empat.

Mulyono, S. (2006). Teori Pengambil Keputusan. Jakarta: Lembaga Penerbit Fakultas Ekonomi Universitas Indonesia.

Nasibu, I.Z. (2009). 'Penerapan metode AHP dalam sistem pendukung keputusan penempatan karyawan menggunakan aplikasi Expert Choice.' Jurnal Pelangi Ilmu, Vol. 2 (5), hal. 180 - 193.

Permadi, E. (2008). Pengaruh Pelatihan Terhadap Produktivitas Kerja Karyawan Pada PT. Asuransi Jiwa Bumi Asih Jaya Distrik Pangkal Pinang. Skripsi, Universitas Widyatama, Bandung.

Rochmasari, L.; Suprapedi, S.; Subagyo, H. (2010). 'Penentuan prioritas usulan sertifikasi guru dengan metode AHP (analytic hierarchy process).' Jurnal Teknologi Informasi, Vol. 6 (1), hal. 115 - 121.

Saaty, T.L. (2003). Decision Making for Leader, The Analytical Hierarchy Process for Decision in Complex World. Pittsburgh: Prentice Hall Co, Ltd.

Suprihanto, J. (2006). Penilaian Kinerja dan Pengembangan Karyawan. Yogyakarta: BPFE UGM.

Wignjosoebroto, S. (2006). Teknik Tata Cara dan Pengukuran Kerja. Jakarta: Guna Widya.

Winkel. W.S. (2005). Manajemen Sumber Daya Manusia. USA: McGraw-Hill. 